\title{
Twenty years of experience in numerical models of historical constructions: a temporal perspective
}

\author{
S. Hernández, L. E. Romera \& J. Díaz \\ School of Civil Engineering, University of Coruña, Spain
}

\begin{abstract}
In this paper some of the studies developed by the authors in the last twenty years in the field of numerical analysis and restoration of historical constructions are presented, with the objective of having a temporal perspective. In all cases the origin of every work was the appearance of several pathologies, that led to structural studies in order to find out the causes of these pathologies and once the way the structure worked and the origin of its problems was understood, the consideration of the necessary restoration. According to our experience, the best way to take into account this difficult and complex process, complementing the engineer's knowledge, is the use of numerical tools like the finite element method. In each of the cases presented, a set of structural models was developed and validated with the aim of simulating the current structural state, their security level and the relationship between the structural behaviour and the damage observed. Comparison of the cases analyzed allows us to obtain several general conclusions.
\end{abstract}

\section{Introduction}

Three cases of study are presented; they have been selected for being in our opinion the most interesting. In the first one, from 1987, the computer aided repair of the Pignatelli Church was presented. This was the first work, developed by our group, in which numerical models are used. After that one appears the identification of structural pathologies of San Martín Tower, the first work that we did combining 3D CAD and visualization models as a previous step to developing a finite element model. And finally the structural study of the Basilica of Pilar in Zaragoza (Spain) is presented. 


\section{Case 1: The Pignatelli Church}

The Pignatelli Church (figure 1), located in the city of Zaragoza, was erected in the middle of the nineteenth century (1859-1866) using masonry bricks. The Church has only one nave which starts with a vault composed of three stretches of unequal length, next is a transept supporting a drum of octagonal section, and above this is placed a dome. An apse is at the rear where the altar is located.

Since 1970, vertical cracks grew from the keystone of each arch of the transept and the restoration was decided on in 1984, by then the cracks were more than a meter long and a few centimetres wide. In 1987 the arch next to the apse had an important part of his masonry nearly cut away, and the cracks progressed into the lateral chapel, broke the rose window and ended at the floor. The dome, drum, vault and columns were very well preserved and did not have any cracks. The work, carried out in 1987 [1], consisted on identifying by means of numerical models the origin of the cracks and deciding the method for repairing the church.
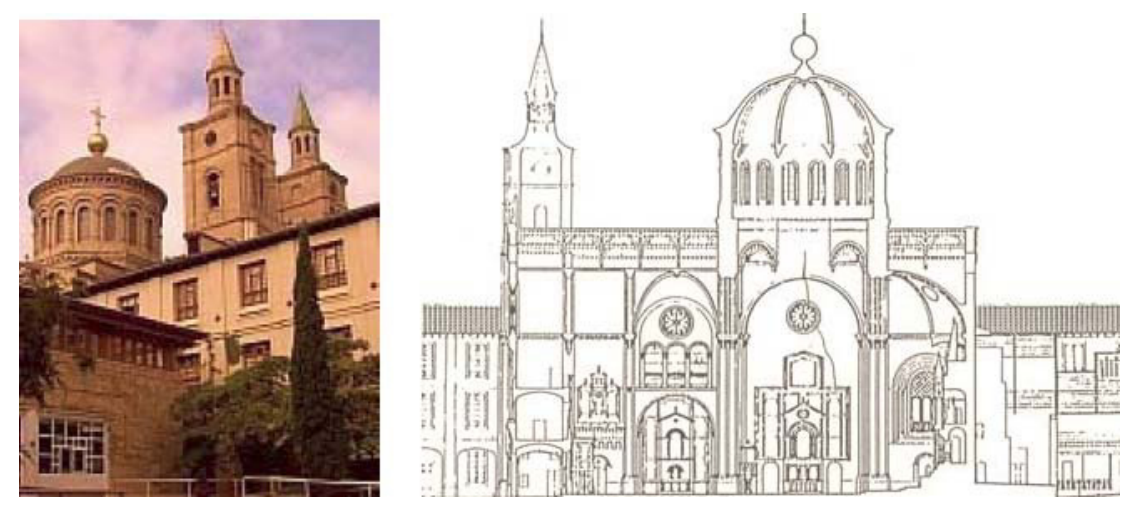

Figure 1: The Pignatelli church: Outside view and cross-section.

The work, carried out in 1987, was intended to identify by means of numerical models the origin of the cracks and define the repairing works. The structural model includes the arches, the columns of the transept and the apse. The dome and the drum have not been included, neglecting their stiffness but including the weight as an external pressure. The complete set weighs up to 1800 $\mathrm{T}$, transmitted to the soil by the columns of the transept and apse.

The mesh (figure 2) used in the analysis had 86 elements (68 shells, 10 beams and 8 springs), 97 nodes and 516 degrees of freedom (DOF). Symmetry was applied and the analyses were carried out on a VAX/VMS 11/750 with SAP4 code [2], and were linear, using an isotropic elastic material for the masonry with mechanical properties: $E=4.5 \times 10^{6} \mathrm{KPa}, v=0.1$ and $\gamma=1.8 \mathrm{KN} / \mathrm{m}^{3}$. Several boundary conditions for columns and foundation were studied. In the case of infinite stiffness foundation, stresses in columns and shell elements were only compressive, and much lower than the compressive resistance for the masonry 
(about $5 \times 10^{3} \mathrm{KPa}$ ). But built-in reactions in columns were very different as shown in table 1 , and they generate stresses that surpassed the allowable stress for the soil foundation considered about of $4 \times 10^{2} \mathrm{KPa}$.
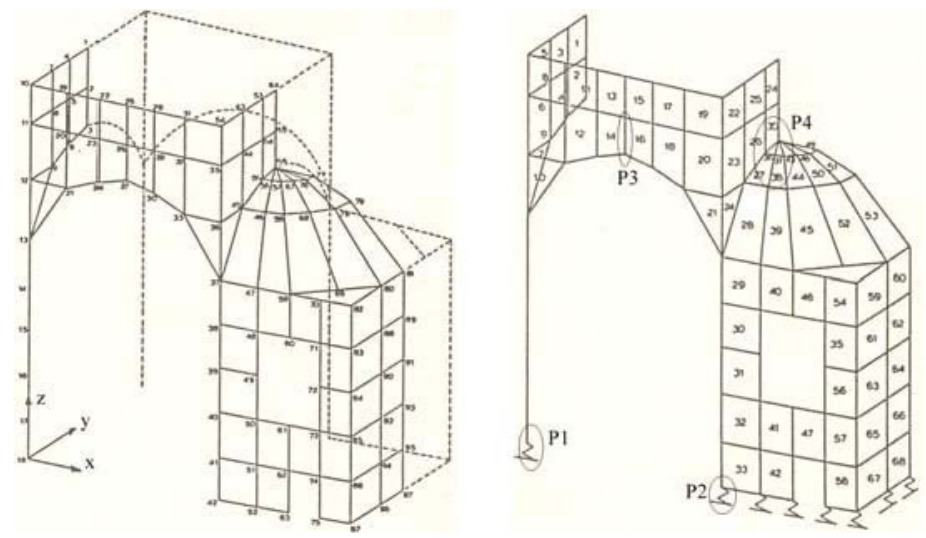

Figure 2: $\quad$ Finite element model.

Table 1: Results in columns basis (positions $\mathrm{P}_{1}$ and $\mathrm{P}_{2}$ are shown in figure 2).

\begin{tabular}{|c|c|c|c|c|c|c|c|}
\hline \multicolumn{4}{|c|}{ Force (KN) } & \multicolumn{4}{c|}{ Moment (KNm) } \\
\hline Position & Axial & \multicolumn{2}{|c|}{ Shear XX Shear YY } & Torsion & $\begin{array}{l}\text { Bend } \\
\text { XX }\end{array}$ & $\begin{array}{l}\text { Bend } \\
\text { YY }\end{array}$ & $\begin{array}{r}\sigma Z \\
(\mathrm{KPa})\end{array}$ \\
\hline P1 & $\begin{array}{c}- \\
6709\end{array}$ & -0.8 & 0.35 & -0.06 & 0.36 & 2.5 & -744 \\
\hline P2 & $\begin{array}{c}- \\
4760\end{array}$ & 70 & -1.2 & -0.06 & -1.2 & -310 & -530 \\
\hline
\end{tabular}

Considering these results, the interaction between soil and structure was included in the model using linear springs with a ballast module of $1.3 \times 10^{5} \mathrm{KPa}$. With this assumption we obtained a vertical displacement in column base $\mathrm{P}_{1}$ of $-42 \mathrm{~mm}$, whereas the column base $\mathrm{P}_{2}$ descends $-16 \mathrm{~mm}$. Results showed that the arch placed in the OXZ plane had rotated in that plane because of differential vertical displacements in columns. Consequently tension stresses appeared in the arch and apse elements near the keystone, with a maximum of $589 \mathrm{KPa}$ in the apse (position $\mathrm{P}_{4}$ in figure 2). As the masonry could not undergo this stresses, the apse broke away from the adjoining arch. To model that breakage several apse elements were eliminated (figure 3(a)) and a new analysis was carried out.

Results from model with cracked apse showing that the central area of the arches had high horizontal tensile stress, with a maximum of $1220 \mathrm{KPa}$ located in the arch next to the apse (position $\mathrm{P}_{3}$ in figure 2). These results explained the existing cracks and the fact that they were more widely distributed in that arch. After this analysis the FE model was modified at the keystones of the arches to 
eliminate collapsed material near cracks (figure 3(b)). When the structure was recalculated, results where quite similar to the former ones and the study ended assuming that convergence had been reached.

From the results obtained it is possible to point out that the structural collapse occurred because soil stresses were too large, and the building is symmetric along a longitudinal plane but not along a transverse plane. Because of that the structure rotates in the OXZ plane, a zone of apse is cut away which leads to a weakness of the general structural scheme.

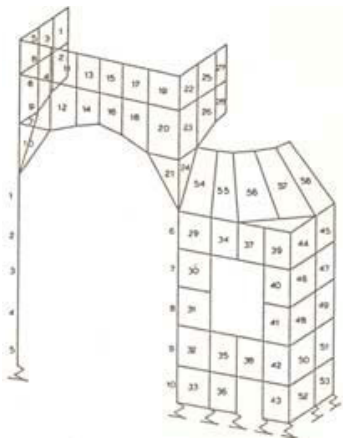

(a) Breakage of apse

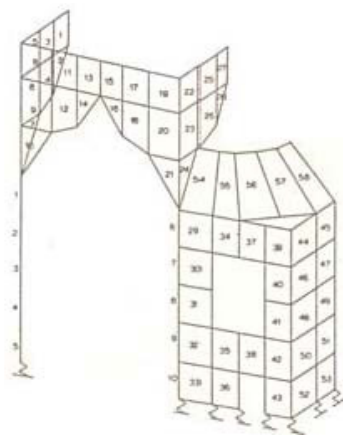

(b) breakage of arch

Figure 3: $\quad$ FE models of collapsed geometry.

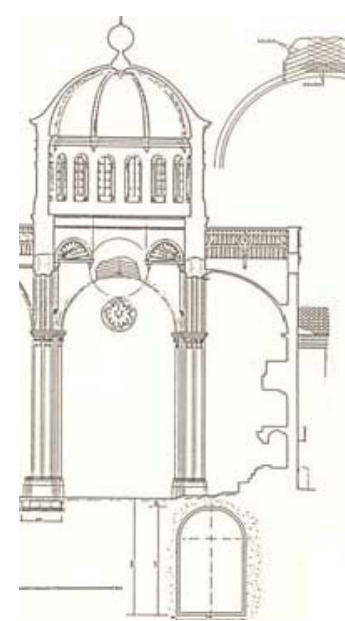

(a) Arches

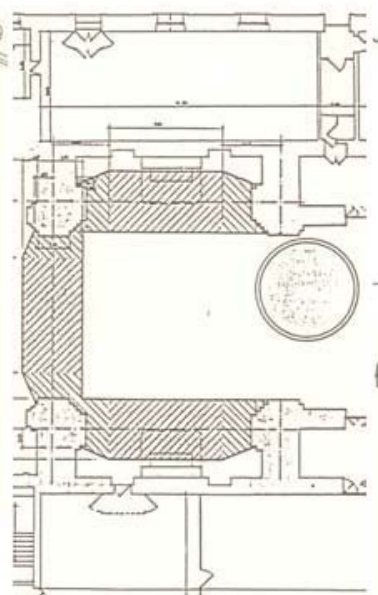

(b) foundation

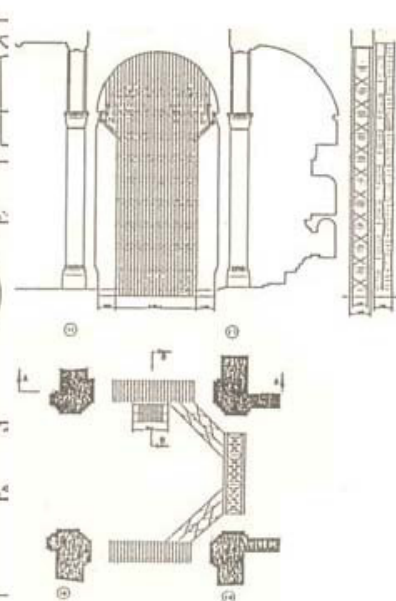

(c) scaffold

Figure 4: Reinforcement works.

The proposed solution for restoration (figure 4) strengthens the structure improving the foundation with four beams of reinforced concrete which join all the columns of the transept, in order to decrease soil stresses and ensure similar movements in column basis. This solution was included in the FE model, obtaining a width of the foundation of $80 \mathrm{~cm}$. When the works of restoration 
began a large empty well used as a water tank was discovered, and it is likely that had contributed to the weakening of the soil by leakage. Another design of foundation was chosen, avoiding the beam placed upon the well.

The damaged masonry was replaced with low density reinforced concrete with the same density as the masonry bricks, connected with steel bars and layers of epoxy resin with the surrounding masonry. The scaffold shown in figure 4 was erected under each arch for the restoration work with several objectives: provide a platform for the repair works, support the load of each arch to remove collapsed masonry, and to dig and rebuild foundations under columns. The new foundations beams served as the foundation for the scaffolding.

\section{Case 2: The San Martín Tower}

The tower of San Martín is an outstanding example of the Mudejar style, built in the XIII century in Teruel (Spain). A number of pathologies were observed and measured and therefore in year 2000 a study of this construction, that allowed establishing the required repairing works, was considered [3].

The building is prismatic, with three sections (figure 5). At street level, the supporting section has a vault with a pointed arch. There is also an intermediate section, which offers an access to the bells, and finally, the upper section. The tower is made of plaster-mortar brickwork, and its buttresses, added at a later date, have been built in stonework. The facades were decorated with crisscrossed brickwork and glazed ceramic pieces. Centered with its exterior counterpart, a second prism makes up the interior. Its first section is of brickwork, while its second section has plaster walls. Between the interior and exterior walls, one finds the system of staircases. A reinforced concrete slab was added to the roof of the bell in an effort to strengthen the original Lombard vault.

The pathologies in the tower of San Martín were vertical cracks along its central section, where it is joined to the adjacent church (figure 6), local buckling in the tower internal passageway (figure 6), tower tilting with western orientation and a magnitude of $50 \mathrm{~cm}$, cracks in its supporting section and along the west buttress and lost of glazed ceramic pieces. The most relevant pathologies appeared in the tower connection to the church as a result of the interaction and excessive lateral pressure appeared in the tower. The next church arch itself displays cracks along the keystone and the dome of the nave side aisle suffered from major cracks.

Along the arches and abutment walls, there were cracks also mentioned in a report written in 1926. It was said that they appeared to be stabilised and, at the time, did not raise the possibility of imminent collapse. This conclusion is corroborated by the tower's behaviour during the last years.

The west buttress, attached to the tower after its erection, had a highly visible vertical crack which almost spans its length. The crack's position corresponds to the way in which the wall is aligned and inclined. The wall itself also revealed defects in the bevelled ashlar stonework, whose joints appeared to be weakened and loosened. Thus, it may be concluded that the crack in the buttress and the structural problems of the wall have the same cause. 

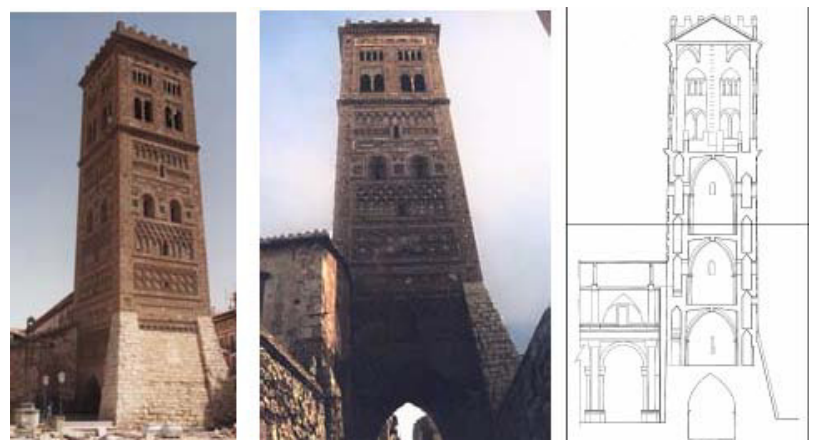

Figure 5: Views of the tower of San Martín and cross-section.

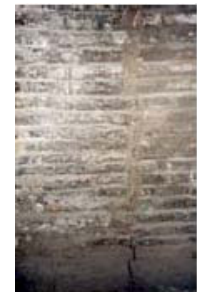

(a)

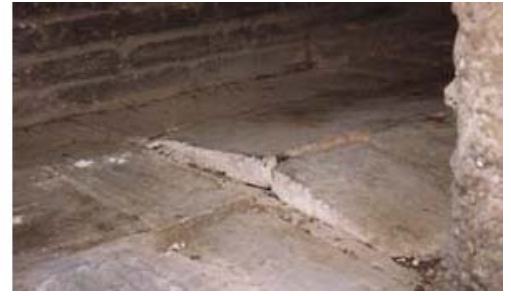

(b)

Figure 6: Pathologies: (a) vertical crack in the wall, (b) buckling along the passageway.

As may be appreciated, the tower of San Martín is a complex building. To gain in-depth knowledge of its structure, a detailed analysis of its geometry is needed. Consequently, a visualisation model was carried out (figure 7(a)) providing a $3 \mathrm{D}$ perspective. With this, it was possible to assess the best way of producing a FE model that faithfully represented the structural behaviour (figure 7(b).

The FE model has 46907 elements, 242030 nodes and 700000 DOF. The supporting section, walls, floors, and staircases and passageways were modeled with solids. Shell and beams were used to model the concrete slab reinforcing the roof, and the bell tower section. The model was completed with a volume of the surrounding foundation ground.

The loads considered in the analysis were the tower's own weight and the thrust church. For the structure's own weight, two hypotheses were looked at: tower in a vertical position with gravitational force aligned with the vertical axis, or tower tilting with western orientation simulated through a gravitational force out of vertical axis. For the interaction between the tower and the church wall it was necessary to simulate several distributions of pressures. The ones which achieved the highest accuracy were the pressure distribution that creates a crack in the wall and local buckling in the passageway similar to real pathologies. 


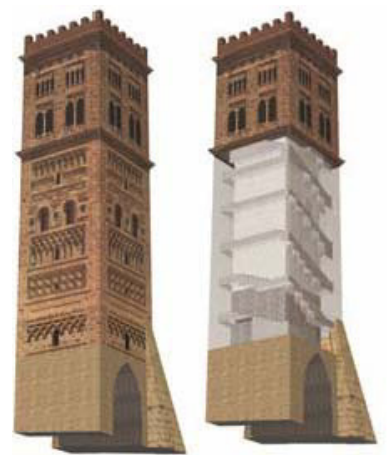

(a)

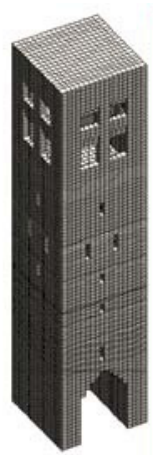

(b)

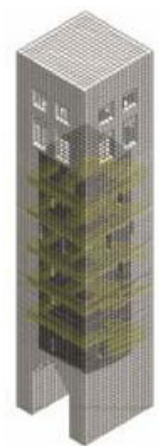

Figure 7: Visualization model (a) and finite element model (b).

The analyses were carried out on a PC Intel 386 using the Cosmos $/ \mathrm{m}$ code [4], and were linear, using an isotropic elastic material for the masonry bricks with mechanical properties: $E=4.5 \times 10^{6} \mathrm{KPa}, v=0.1$ and $\gamma=1.8 \mathrm{KN} / \mathrm{m}^{3}$.

From the results we conclude that differences between the vertical model and the tilted one are not significant. The predominant stresses are compressive (figure 8(a)) with a maximum of $1400 \mathrm{KPa}$ in the supporting section. The ground stress reaches $500 \mathrm{KPa}$, minor than the limit of $1000 \mathrm{KPa}$ from the geotechnical data. This situation and the harsh climatic conditions could explain why there had been subsidence before the buttresses were added. The tower facing adjacent to the church had probably shifted outwards before the buttresses erection.

The next step was to take into account cracks by deactivating the connectivity between finite elements where tensile stress appeared. Results show that tensile stresses have been released once the cracks are incorporated into the model. The final set of analysis is related to the application of different load distributions along the tower wall adjacent to the church, simulating an interaction between the two structures. An examination of the results led to the conclusion that the thrust resembles a rectangular load defined within a localised area. The stress distributions related to these load are presented in Figure 8(b) and 8(c). The proposed solutions for restoration were:

- The cracks in the central section connected to the adjacent church and local buckling in the tower's passageway were due to the church deterioration. It would be necessary to separate the two edifices, to avoid this thrust.

- The origin of tower tilting cannot be pinpointed; it may be linked to the tower's construction or could be due as a result from the varying degrees of subsidence due to unequal stress distributions along the foundation. In any case, this analysis does not lead one to believe that the tower's collapse is worsening.

- For the cracks in the supporting section, they probably resulted from previously existing factors. Therefore, they should not worsen. In the case of cracks along the west buttress, due to their structural importance, it would be advisable to make it independent of the nearest containment wall, and avoid instability caused by deterioration in the material used as filler. 


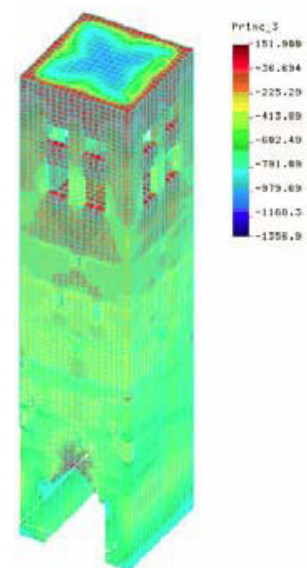

(a) Principal compressions

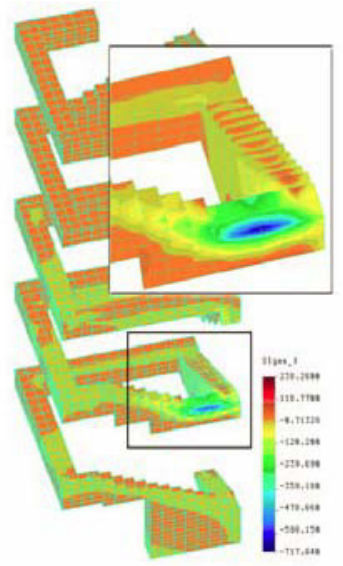

(b) Detail of $\sigma \mathrm{x}$

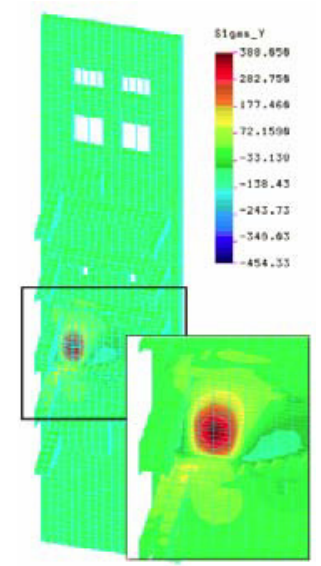

(c) Detail of $\sigma y$

Figure 8: $\quad$ Stress results $(\mathrm{KPa})$.

\section{Case 3: The Basilica of Pilar}

The Basilica of Pilar, located in the city of Zaragoza (figure 9), is one of the best known Spanish cathedrals. The temple is a large and complex brick masonry construction, with three longitudinal naves. The central one contains the main dome of double shell, and two more elliptical domes. The lateral naves have eight more domes, and surrounding the complex there is a system of chapels and rooms. Four towers of more than $90 \mathrm{~m}$ height mark the building corners.

Their construction was long in the time and difficult [5]. A thousand years ago, a small Visighotic chapel had been built; later on became a Romanesque church with cloister that will suffer posteriorly a Gothic enlargement. The huge extension took place in XVII century when the baroque church was set up, the central dome rises in 1850, and the last towers are erected in 1940. Several domes contain frescoes by Francisco de Goya, and some of them have suffered damages, in particular the frescoes of dome Regina Martirum are being restored at the present time. A set of structural models were developed and validated in 2005 with the aim of simulate the structural state, their security level and the relationship between the structural behaviour and the damages observed [6].

Figure 1 presents a sketch describing the position of each building along the history, and Figure 2 shows plans and several views of the actual temple.

In the year 1796 the first references appear about fissures in arches, tambours and vaults, especially in elliptical domes. In year 1927 symptoms of general ruin appear, cracks of relevant size could be seen in arches; pillars were out of their vertical orientation and important relative displacements were observed in the Regina Martirum dome. A programme of repairing works was approved and the rehabilitation task continued until 1940. The most important features of the restoration (figure 10) were: an extensive injection of cement grouting in the soil, foundation improvement with $\mathrm{RC}$ beams linking steel caissons at pillars 
foundation, temporary support and steel reinforcement of arches and pillars, external reinforcement of several tambours by $\mathrm{RC}$, and installation of inclined supports in tambours, connecting them with external buttress.
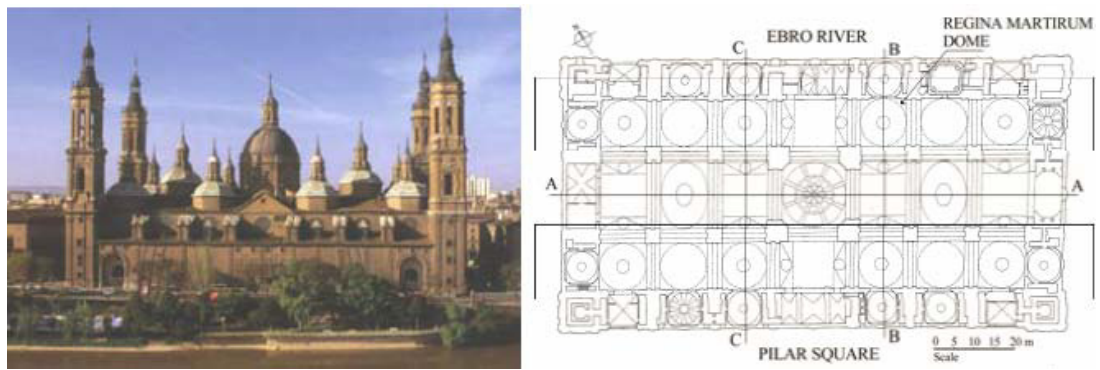

Figure 9: External view and inferior top view.

A few years ago other structural pathologies, of a smaller entity that the aforementioned, but significant due the affection of frescoes were observed: presence of humidity, small fissures and lost of material in frescoes of Regina Martirum dome, cracks in several arches, and deterioration of masonry towers.

To determine if the damage of frescoes could be due to structural pathologies, and if this was the case, to outline the necessary actions to correct them, an extensive numerical study was carried out. FE models were used to simulate the temple global structural behaviour and the local one of Regina Martirum dome.

The approach used in the study is described in figure 11. Due to geometrical complexity and the structural dimensions, a 3-D digital model of the church was generated first. This geometrical model allowed to understand the architecture and to realize the construction connectivity. Starting from this model the visualization model and several structural models were developed (figure 12).

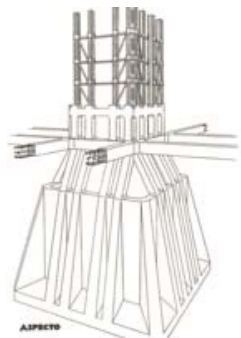

(a) Foundation caissons

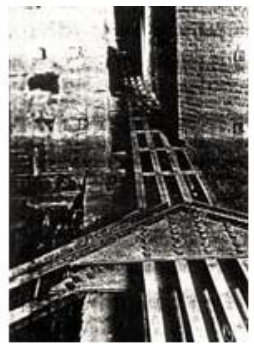

(b) Steel bonds

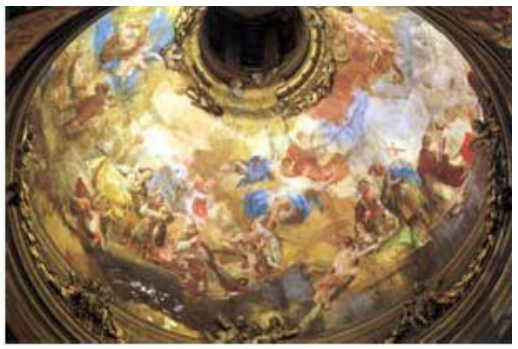

(c) Regina Martirum frescoes

Figure 10: Repair work in 1940 and actual state of Regina Martirum Frescoes.

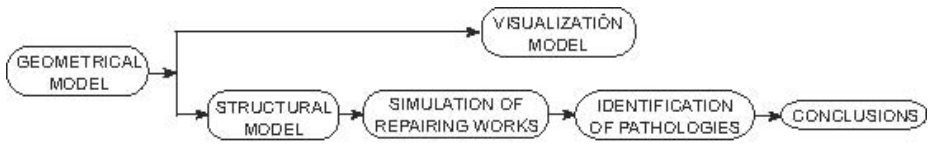

Figure 11: Flowchart of methodology. 
The analyses made are linear and non linear, including the constructive process and the reinforcement works added to the structure along their history. We developed global models of the whole temple and local models to study in detail the behaviour of Regina Martirum dome. To carry out them the codes Cosmos/m and Msc.Marc [7] have been used, combining several types of elements: hexahedral and tetrahedron elements for modelling arches, pillars, tambours, buttresses and soil foundation, whereas beam, bar and shell elements were selected for domes, floors, walls and reinforcements structures.

The first global model represents the temple before the repairing works of 1927. Therefore a FE mesh including the temple and a volume of the surrounding soil was created (figure 12). The comparison between their results and the existing descriptions of past pathologies allowed us to check the model. After that, a new one representing the current state of the temple was created.
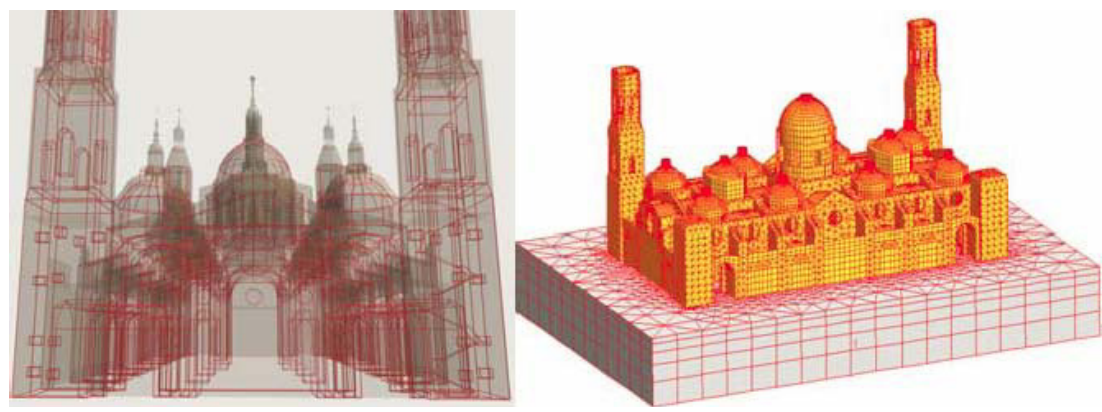

Figure 12: Visualization model and global FE model.

The results from this model, with soil properties enhanced due to reinforcements, are almost identical to those obtained with fixed basement. Thereby, the soil was eliminated in the actual state model. For each model a first version with linear elements (82000 elements and 140000), and a second with quadratic elements were carried out. The loads were composed of gravity loads including dead loads, a uniform thermal load $\Delta \mathrm{T}= \pm 15^{\circ} \mathrm{C}$ in the whole temple, and a thermal gradient in the Regina Martirum dome, produced by a temperature difference of $\pm 15^{\circ} \mathrm{C}$.

First a linear analysis was made with isotropic materials and a typical range of values for brick masonry [8]. In the 1927 model two hypotheses about the soil properties distribution were carried out to take in account the possible deterioration in the soil near the riverside. Regarding to the principal masonry pillars, with cross section about $36 \mathrm{~m}^{2}$, one material with a reduced elasticity modulus was considered to simulate the existence of a filled nucleus. After linear analysis, two nonlinear isotropic material models were programmed for the masonry, with brittle behaviour in tension and linear in compression, or considering plasticity in compression using a Mohr-Coulomb model [9].

In the year 1927 model, with linear material and a uniform soil, principal tensile stresses reaches a maximum values of $900 \mathrm{KPa}$, and $2400 \mathrm{KPa}$ in compression (Figure 13). Both values overcome the allowable range for 
masonry. The main cause of these significant values is the excessive weight coming from the central dome. Principal tensile stresses distribution agrees with the description of structural damages in that time, with maximum values in arches and vaults surrounding the central dome. However there is no evidence of important tensile stresses in elliptic domes tambours, in contradiction with historical reports.

Considering a non linear material model with cracking stress $\sigma_{\mathrm{cr}}=150 \mathrm{Kpa}$, residual stress $\sigma_{\mathrm{res}}=0.1 \sigma_{\mathrm{cr}}$, discharge modulus $\mathrm{Es}_{\mathrm{s}}=0.1 \mathrm{E}$, and a retention shear factor of 0.01 for cracks, allow us to demonstrate that cracks begins in arches and progress by the tambours of the elliptic domes, due to the transversal rotation that imposes them the excessive weight of central tambour and dome.

It is necessary to highlight the influence in stress results if an evolutionary model considering the constructive stages is included in the simulation, even with linear material models. Globally, stresses decrease in towers and superior parts, especially in the most slender like domes, and they are increased in central pillars and arches. A probably procedure for temple construction could consists on four stages, without temporally scaffolding: step 1 (pillars and arches), step 2 (tambours and perimeter walls), step 3 (vaults and domes), and step 4 (towers in three new stages). In such case stresses decrease approximately $50 \%$ in tambours, domes, vaults and towers, and are increased in the arches $70 \%$.

For the actual state model, the sequential application of the repairing additions has allowed to check their relative effect, being this especially significant in the case of foundation works and steel lining of pillars and arches. Considering linear material properties and all the rehabilitation works applied, the maximum principal stresses in masonry decreases to $102 \mathrm{KPa}$ for tensile stresses in arches keystone, and to $1123 \mathrm{KPa}$ for compression stresses in pillars.
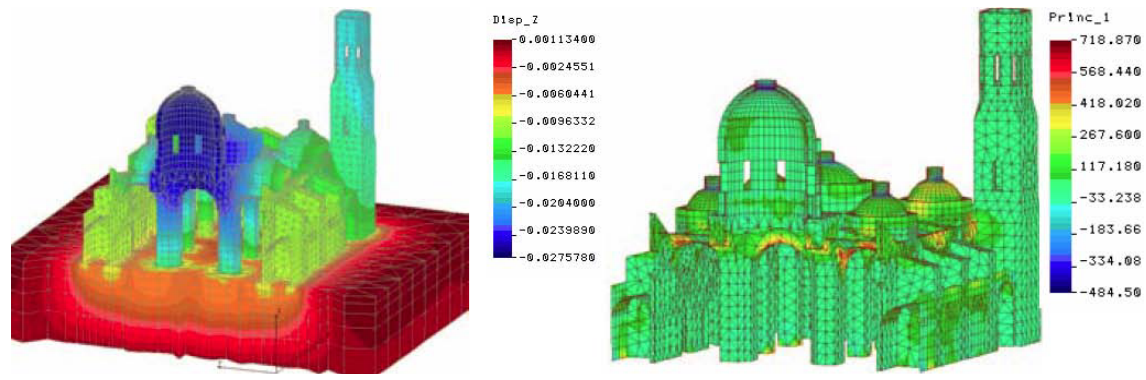

Figure 13: Vertical displacement $9 \mathrm{~m} 0$ 9left0, and principal tensile stresses (right) $(\mathrm{KPa})$.

Considering nonlinear material, a local analysis of Regina Martirum dome modelled has been carried out. The movements obtained in the dome base from the global model have been imposed as constraints to the base dome in local model. To study the limit collapse, instead of increasing external loads, a collapse mechanism was found by varying the material nonlinear parameters with current loads. With the cracking stress as variable the collapse takes place with a value of $70 \mathrm{KPa}$, lower but close to the habitual value of $100 \mathrm{KPa}$. 
Numerical models shown that the current structural situation of Regina Martirum dome is satisfactory and there is no risk of pathologies. Globally the structural situation is good, except in the towers, due to environment deterioration of brick masonry. Actually the restoration of the Regina Martirum frescoes is being finalized, and they are being developed reparation works of covers and towers.

\section{Conclusions}

The comparison of the analysis presented allows us to extract some conclusions.

- The development of computers and structural programs allows at the present time to analyze complex models with millions of DOF, simulating the structural behaviour by means of linear models or with more precise and complex nonlinear models. The use of linear models as a previous step to nonlinear analysis, allows us in most of the cases to comprehend the real structural behaviour, with less computational cost and complexity, and they act as a guide for the subsequent nonlinear analyses.

- Due to the complexity of structural behaviour, especially true in the case of historical constructions by the temporary evolution of mechanical and geotechnical properties or his spatial variation, it is not valid to think that the numerical results obtained for stresses, strains and displacements are exact. But these models, along with other types of analysis as limit analysis and with experimental data, allow identifying the guidelines of the structural behaviour and the validity of restoration works.

- The previous realization of detailed geometrical model facilitates the generation of complex models with parametric or unstructured meshing.

- Numerical models can allow to determine structural historical pathologies, and to check out the efficiency of restoration works developed in the past.

- In historical structures usually the consideration of geometrical nonlinearities gives results very similar to those obtained considering the linear theory, due to the small movements that take place in massive and rigid structures, because of that normally only the material nonlinearities being considered.

- The consideration of nonlinear constructive process and its application with a staged geometrical nonlinear analysis produces considerable changes in the stress distribution.

\section{Acknowledgements}

Thanks are due to J. Mata, A. Solozabal, J. Cascales, A. Sanchez, I. Valcarce, P. Loscos, and J.M. Reinosa, former research assistants of the U. of Zaragoza and Coruña, for their contribution to the studies mentioned in this paper. 


\section{References}

[1] S. Hernández, J. Mata, A. Solozabal. A Computer Aided Repair (CAR) Case Study: The Hogar Pignatelli Church at Zaragoza, C.A. Brebbia ed. Structural Repair and Maintenance of Historical Buildings, (1989).

[2] K. J. Bathe, E. Wilson. SAP IV (A Structural Analysis Program for Static and Dynamic Response of Linear Systems). University of California, 1974.

[3] S. Hernández, J. Cascales \& P. Loscos. Identification of Structural Pathologies of San Martín Tower. C.A. Brebbia ed. Structural Studies, Repairs and Maintenance of Heritage Architecture VII, (2001).

[4] COSMOS/M v.2.8. Finite Element Analysis System: I) User Guide, IV) Advanced Modules. Structural Research \& Analysis Corp., (2003).

[5] T. Ríos Usón and T. Ríos Solá, El Pilar de Zaragoza, CAI ed. (1983).

[6] L.E. Romera, S. Hernández \& J.M. Reinosa. A Comprehensive Structural Study of the Basilica of Pilar In Zaragoza (Spain), C.A. Brebbia ed. Structural Studies, Repairs and Maintenance of Heritage Architecture IX, (2005).

[7] MSC. MARC 2003. Vol. A Theory and User Information, (2003).

[8] P.B. Lourenço, Experimental and numerical issues in the modelling of the mechanical behaviour of masonry. P. Roca, J.L. González, E. Oñate and P.B. Lourenço eds. Structural analysis of historical constructions II. Possibilities of num. and exp. tech., CIMNE, pp. 57-92, (1998).

[9] Computational Modelling of Masonry, Brickwork and Blockwork Structures. J.W. Bull (ed.), Saxe-Coburg Publications, (2001). 